\title{
Sensibilizar a natureza humana interior: a unidade homem-natureza e a educação ambiental
}

\author{
Denise Gamio Dias \\ Neiva Afonso Oliveira \\ Avelino da Rosa Oliveira \\ Universidade Federal de Pelotas
}

\section{Resumo}

0 artigo busca contribuir filosoficamente para uma fundamentação mais consistente da Educação Ambiental, a fim de possibilitar a melhoria da saúde pública nas comunidades, através da prática preventiva de doenças. Em primeiro lugar, o texto apresenta a relação entre saúde pública e educação ambiental; em seguida, faz um resgate filosófico-histórico a respeito da relação homemnatureza, argumentando que a natureza é elemento intrínseco à condição humana. Por fim, defende a ideia de que o emergir de atitudes de sensibilização humana frente à natureza não é discordante com uma ontologia de aproximação homem-physis, sempre presente na história humana. A tese defendida é a de que a abertura para a sensibilidade humana aproxima os três campos do conhecimento (saúde pública, educação ambiental e filosofia), sendo a ponte que resgatará elementos perdidos, recalcados ou esquecidos com a cisão homem-natureza ocorrida, mais expressivamente, na Ciência Moderna, através da dicotomia sujeito-objeto do conhecimento.

Palavras-chave: Natureza. Filosofia. Sensibilidade. Educação ambiental. 


\section{Sensitizing the inner human nature: man-nature unity and environmental education}

This paper seeks to contribute with a philosophical approach to a more consitent foundation of Environmental Education, in order to make possible the improvement of public health in communities through disease-prevention practices. Firstly, the text shows the relationship between public health and environmental education; next, it brings a philosophical and historical comprehension of the man-nature relationship, claiming that nature is an intrinsic aspect of the human condition. Lastly, it supports the idea that the emergence of attitudes of human sensitization towards nature is not antagonistic with an ontology that has always been present in human history and that approximates man and physis. The thesis supported in the paper is that the acceptance of human sensibility can bring together three fields of knowledge (public health, environmental education and philosophyl and might be a bridge to restore elements which have been lost, repressed or forgotten with the man-nature split that took place more expressively with modern science, which clearly dichotomized the subject and the object of knowledge.

Keywords: Nature. Philosophy. Sensibility. Environmental education.

\section{Sensibilización de la naturaleza humana interior: la unidad hombre-naturaleza y la educación ambiental}

El trabajo contribuye a una fundación filosófica más coherente de la Educación Ambiental, a fin de mejorar la salud pública en las comunidades a través de prácticas de prevención de enfermedades. En primer lugar, el texto presenta la relación entre la salud pública y la educación ambiental, y luego hace un rescate filosófico-histórico sobre la relación entre el hombre y la naturaleza, con el argumento de que la naturaleza es intrínseca a la condición humana. Por último, defiende la idea de que la aparición actitudes de sensibilización humana delante de la naturaleza no es discordante con una ontología de aproximación hombre-physis, siempre presente en la historia humana. El argumento es que la apertura a la sensibilidad humana acerca los tres ámbitos de conocimiento lla salud pública, la educación y la filosofía ambientall, siendo el puente que vá rescatar los elementos perdidos, olvidados o reprimidos con la división hombre-naturaleza, que se produjo más expresivamente en la ciencia moderna, por la dicotomía sujeto-objeto de conocimiento.

Palabras-clave: . Filosofía. Sensibilidad. Educación ambiental. 


\section{Introdução}

No último quartel do século XVIII, buscando determinar as condições de possibilidade do conhecimento, Immanuel Kant já advertia que a frequente discórdia entre os que se dedicam a um mesmo campo de estudo, a insegurança em atingir suas metas ou a necessidade de, a cada momento, voltar atrás e refazer os caminhos percorridos revelam que tal área de conhecimento está ainda longe de um caminho seguro, tratando-se, isto sim, de "mero tatear". Entretanto, está convencido o Filósofo de Königsberg de que a consciência desta fragilidade põe-nos no rumo de sua superação, “sendo já grande o mérito da razão em ter descoberto, de qualquer modo, esse caminho, mesmo à custa de renunciar a muito do que continha a finalidade proposta de início irrefletidamente." (CRP, B VII - KANT, 2001, p. 41)

Mutatis mutandis, essa reflexão que antecede a Crítica da Razão Pura é atual, ainda hoje, nas diversas áreas que lidam mais diretamente com a noção de ambiente, como é o caso, por exemplo, da saúde pública e, especialmente, da educação ambiental. A falta de uma compreensão filosoficamente mais apurada do conceito de natureza impede que tenham uma fundamentação sólida em seus misteres teórico-práticos. Nesse sentido, já foi possível constatar que as pesquisas conduzidas no campo da saúde pública pouco conseguem extrapolar a análise empírico-científica de dados quantitativos e enveredar pela hermenêutica da relação homem-natureza. Assim, quando se vê diante de limites instransponíveis, deposita sua confiança numa genérica ideia de educação ambiental, capaz de conduzir as populações a hábitos de cuidado com o ambiente em que vivem, a fim de que este não se torne promotor da doença. Mais grave ainda é o fato de a própria educação ambiental, por muitos de seus praticantes, ainda não dispor de suficiente clareza e definição quanto a seus objetivos e métodos de ação e avaliação, conforme reconhecem Guimarães (1995) e Reigota (1995). A falta de fundamentação teórico-metodológica na educação ambiental leva a atividades desarticuladas pedagogicamente e ineficazes ou insuficientes para a transformação dos educandos via aquisição de novos hábitos, posturas e condutas frente ao caos ambiental que vivemos (Pedrini, 2002, p. 92). Além disso, a pluralidade de concepções a respeito de educação ambiental que começam a despontar, sobretudo a partir do ano 2000, e que, nesse momento, ainda recebem variadas adjetivações, revela que no momento da instituição da Política Nacional de Educação Ambiental (PNEA) havia uma clara indefinição de como se desenharia um campo político-ideológico que pudesse consolidar os diversos modelos possíveis desse fazer educativo. Assim, da mesma forma que não estavam dadas as condições sociais nem acadêmicas, também não estavam dadas as condições políticas para a institucionalização da PNEA no país. (Layrargues, 2003, p. 54)

Embora cientes das tensões e contradições existentes nos períodos históricos em que foram sendo produzidas as relações homem-natureza, no presente artigo, 
propomos um estudo filosófico do conceito de natureza, com o intuito de buscar fundamentação teórica para a educação ambiental, possibilitando o resgate de aspectos que foram relevantes ao longo da história da filosofia. Acreditamos que uma reflexão filosófica consistente e consequente há de impulsionar o avanço da educação ambiental enquanto campo do conhecimento e pode possibilitar a melhoria da saúde pública nas comunidades através da prática preventiva de doenças - espaço, por excelência, exercido pela educação ambiental. A reflexão filosófica, sem dúvida, pode auxiliar na crítica ao modo como a objetificação da natureza e do ambiente acabou por objetificar o próprio homem que, hoje em dia, assistindo ao esgotamento dos recursos naturais, encontra-se refém de sua própria prática.

Ao marcar compreensões paradigmáticas do conceito de natureza na história da filosofia - por considerar que este movimento seja capaz de auxiliar-nos a superar a visão utilitarista e reducionista que tem presidido muitas das discussões sobre este tema -, direcionamos nosso olhar para a descoberta daqueles aspectos do ambiente, contemplados ao longo da tradição da filosofia da natureza e, posteriormente, negligenciados em favor de concepções que acabaram se fortalecendo como a tônica da compreensão de natureza no mundo ocidental.

A discussão sobre a problemática ambiental pode ser acompanhada pela reflexão sobre o conceito de natureza e, caso recorramos à análise antropológica sobre a questão, tão mais produtivo e alargado deverá ser nosso entendimento sobre o assunto. Para compreendermos o significado do conceito de natureza, em suas mais variadas formulações no espaço e no tempo, é necessário reconhecer os contextos nos quais se encontra inserido e elucidar esses contextos e teias de significação. Este pensar remete-nos a Abrantes (1998), quando faz referência à historicidade do conceito de natureza.

Nossas concepções a respeito das entidades que constituem a natureza, suas propriedades e suas inter-relações sofreram mudanças, às vezes radicais, ao longo do tempo. Os recortes que fazemos do real, nossas classificações das entidades e dos processos naturais variaram de época para época, refletindo-se em nossas teorias, chamadas a explicar os fenômenos observados. (Abrantes, 1998, p. 9-10)

Para uma abordagem histórico-filosófica do conceito de natureza, optamos por apresentá-lo a partir de alguns sentidos preponderantes que adquiriu em diferentes momentos e contextos históricos. Com tal opção, não pretendemos afirmar que seja possível isolar qualquer compreensão monolítica e absolutamente determinada, desconhecendo as tensões e contradições sempre presentes na história da filosofia. 0 que queremos é ressaltar certos modos que se estabeleceram como predominantes no entendimento sobre o conceito de natureza. Reiteramos que isso, em absoluto, significa que cada compreensão subsista sozinha ou que uma vá sendo simplesmente substituída pela outra como se fossem etapas subsequentes. 
Na realidade, os vários modos de pensar coexistiram, muitas vezes apenas um predominando num período, enquanto os outros permaneciam com menor relevância. Desse modo, embora reconhecendo os méritos de tantas outras formas de apresentação do problema, recorremos a uma estratégia diferente daquela adotada, por exemplo, por Collingwood (1889-1943), que subdivide a história do pensamento europeu com base em estágios consecutivos e progressivos, indicando passos em que a ideia de natureza foi posta em foco pelo pensamento, esteve completa como ideia abstrata, avançou sem hesitar e o período em que, erguendose sobre a ideia abstrata, uma superestrutura de ciência natural pormenorizada foi particularizada e rompeu vínculos de reconhecimento mútuo entre homem e natureza.

\section{A physis como totalidade holística}

De acordo com Jaeger, a physis designa um processo de surgir, de desenvolverse e também abarca "la fuente originaria de las cosas, aquello a partir de lo cual se desarrollan y merced a lo cual se renueva constantemente su desarrollo; en otras palabras, la realidad subyacente a las cosas de nuestra experiencia" (Jaeger, 1977, p. 26). Assim, segundo o autor, é possível notar dois aspectos inseparáveis no conceito grego de physis: o problema da origem e da compreensão por meio da investigação empírica.

Evidencia-se, dessa forma, que o caráter holístico da noção de physis faz referência à totalidade das coisas no mundo, revelando-se um conceito complexo e abrangente, que busca sempre o primário, o fundamental.

A physis, para os gregos, tem um significado muito mais rico. Significa a origem e, até, a totalidade. Inquirir sobre a physis de algo era remontar à sua matriz primeira. Inquirir sobre a physis, sem qualquer especificação, era, então, remontar à matriz primeiríssima, de onde tudo brota. A physis era matriz e nutriz de todo o processo real. Para os gregos, nada acontecia fora dela. Deuses e homens, animais e plantas, enfim, toda a totalidade era como que abarcada e englobada pela physis e na physis vivia ou existia, por ela e nela. (Lara, 1989, p. 45-46)

Essas características revelam que o conceito de physis é assim amplo e radical porque diz respeito a tudo aquilo que existe e, por isso, não há nada fora da physis que possa ser objeto da investigação humana. Nessa perspectiva, engloba tudo o que é, inclusive o homem. 0 mundo é um caos ordenado, cuja organização se assemelha a certo tipo de ordenamento dentro da mente humana, sendo possível uma análise racional do mundo empírico. Ao pensar a physis, os filósofos présocráticos não visam construir um pensamento naturalista; antes, a preocupação concentra-se em pensar o ser. A utilização de elementos físicos como a água, a 
terra, o ar ou o fogo para explicar a origem do universo não faz mera referência aos elementos da natureza, mas representa uma tentativa de aproximação e compreensão do ser. 0 conceito de physis, portanto, "representa o cosmo, o universo, tudo o que existe." (Picht, 1989, p. 363)

\section{Natureza e hierarquia monoteísta}

Desde a ascensão e queda da cultura helênica, a tomada do poder político pelos romanos e admissão do que denominamos "cultura clássica", consolidase aquilo que os gregos legaram à cultura moderna, ou seja, o racionalismo crítico. Este, de certa forma, sempre incomodou o dualismo matéria e espírito levado a termo pelo Cristianismo e que, até nossos dias, nos acompanha quando, por exemplo, analisamos e colocamos em xeque a relação que mantemos com o ambiente, como se fôssemos distintos dele. A mais forte contraposição ao racionalismo crítico dos gregos é o dualismo cristão, que começa a arraigarse em nossos raciocínios a partir do medievo. Nesse período, instala-se como que uma nuvem maniqueísta, que faz sombra à imaginação e à sensibilidade. Os legados a nós deixados a partir de então são, entre outros, uma hierarquia monoteísta do Cosmo, o reforço do dualismo espírito-matéria do platonismo que, embora seja dualismo, permite fazer respirar no mundo uma aura de significado sobrenatural e teísta. Tal herança acaba por separar e fazer diversos homem e natureza.

Kesselring (2000) apresenta a reflexão de que, na Idade Média, a natureza é âmbito da criação. E, especialmente a partir do século XII, impõe-se a questão da relação entre a sabedoria grega (Sophia) e a verdade cristã, pois, no século XII, as obras de Aristóteles tornaram-se gradativamente conhecidas. Entre os pensadores que lutaram para lograr uma síntese entre o pensamento grego e a convicção cristã, o mais importante foi São Tomás de Aquino. A ideia aristotélica, segundo a qual a natureza é o princípio interno de movimento e repouso, convenceu muitos medievais e foi defendida por vários pensadores eminentes. Por razões óbvias, no entanto, acrescentou-se que quem atribui a cada ser a sua determinação individual, isto é, a physis, é Deus. Com isso, muda-se a imagem da natureza fora do homem, assim como a imagem da natureza dentro do homem. Após a criação divina do universo, acontece a admissão da criação do homem como o ser escolhido para dominar e transformar a terra, participando da obra da criação. A humanidade, na interpretação de escritos do criacionismo, passa a entender-se como detentora do poder sobre as coisas, diferenciando-se dos outros seres e entendendo que até mesmo seu alimento é diferente e melhor do que aquele dos demais animais.

0 pensamento judaico-cristão, nesse sentido, foi decisivo para a separação 
entre homem e natureza. Na base do cristianismo, está a ideia de que Deus criou o homem - filho dileto - à sua imagem e semelhança, dotando os seres humanos de privilégios em um mundo imperfeito. A visão antropocêntrica de mundo que começa a tomar corpo permite aos seres humanos dominar a natureza, uma vez

que esta se torna um espaço dessacralizado, onde já não há mais deuses. É com essas duas perspectivas que se constitui como paradigma a visão renascentista de homem e de natureza.

\section{Natureza como inteligência para além dela mesma}

De acordo com Collingwood, a visão renascentista de natureza começa a formar-se como antítese à visão grega, primordialmente, nas obras de Nicolau Copérnico (1473-1543), Bernardino Telesio (1508-1588) e Giordano Bruno (15481600). 0 ponto central desse antagonismo era a negação de que o mundo da natureza, o mundo estudado pela ciência física, fosse um organismo e a afirmação de que era desprovido de inteligência e de vida, portanto, incapaz de ordenar os seus próprios movimentos de uma maneira racional. Os movimentos manifestos são impostos pelo exterior e as regulações desses movimentos ocorrem devido a leis da natureza impostas pelo exterior. Em vez de ser um organismo, o mundo natural, nessa concepção, é uma máquina utilizada para um fim definido por um espírito inteligente que the é exterior. Os pensadores da Renascença, tal como os gregos, viam na ordenação do mundo natural uma expressão de inteligência. Para os gregos, essa inteligência era característica da própria natureza; para os pensadores renascentistas, em oposição, era a inteligência de algo para além da natureza - o criador divino e senhor da natureza. Eis a diferença entre a ciência natural grega e a renascentista.

Nos estudos de Lenoble (2002), o conceito de natureza aparece relacionado às formas de consciência que orientam a experiência.

[...] quinze séculos de pensamento cristão aglomeram num todo uma moral, uma filosofia, uma legislação civil - o que une todos esses elementos é a razão, a razão natural; a natureza conforma-o pela sua autoridade - o mundo de Dante; a seguir, a razão fornece os motivos que recomendam a fé. A cristandade é o mundo civilizado, assim, não podem existir outras leis, uma outra razão, uma outra natureza. (Lenoble, 2002, p. 236)

0 mesmo autor acrescenta que, para o homem do Renascimento, a natureza toma, pois, o lugar de Deus, porque ela própria possui uma alma, realiza constantes intenções e é vista pelo homem como uma Providência. Em certo sentido, Lenoble corrobora a análise marxiana em “A Ideologia Alemã”, de que 
[...] os idealistas, sejam eles filosóficos ou religiosos, antigos ou modernos, acreditam em inspirações, em revelações, em salvadores, em milagreiros; o fato de essa crença assumir ora a forma tosca religiosa, ora a forma erudita filosófica depende apenas do seu grau de instrução, assim como depende unicamente da medida de sua energia, de seu caráter, de sua posição social etc., se adotam um comportamento passivo ou ativo em relação à crença milagrosa, isto é, se são pastores milagreiros ou se são ovelhas, se, ao sê-lo, perseguem fins teóricos remotos ou fins bem práticos. (Marx; Engels, 2007, p. 511-12)

Na época do Renascimento, é a forma erudita filosófica que se manifesta e, por sua tentativa de juntar e harmonizar cristianismo e espírito clássico, o mundo (physis) surge como um elemento a ser explorado pelo homem que, de criatura vil e pecadora, passa a ser protagonista e interventor no mundo físico. Da história, temos a confirmação de que, nesse período, inúmeros instrumentos científicos foram inventados e diversas leis naturais e objetos físicos, outrora desconhecidos, foram descobertos.

\section{Natureza súdita, razão soberana}

O projeto moderno, cujo ápice é o século XVIII, caracteriza-se pela soberania da razão, pela legitimação do sujeito, que se vale de sua subjetividade recuperada para imprimir no objeto seu modo de conhecer. 0 maior grau de conhecimento fornecido pela ciência a partir da razão humana explica o mundo por métodos de interferência e transformação da realidade - é a completa e irreversível secularização da razão. 0 pensamento moderno tem como exigência o antropocentrismo, enquanto pressupõe o condicionamento do objeto pelo sujeito. 0 homem assume o centro como o único capaz de fundamentar o conhecimento racional e empírico.

Aí, podemos observar uma certa ironia da história que abre caminho ao domínio da razão construtiva do homem sobre o real, pois foram as tentativas de aperfeiçoar a representação gloriosa de Deus-criador que levaram o homem à descoberta das leis de construção do mundo, voltando-se, desse modo, à pretensa autocelebração da ordem divina, através de obras-testemunhos do poder divino, contra seus próprios fundamentos teológicos para, finalmente, levar à sua destruição. (Flickinger, 1998, p. 367)

A convicção baseada na crença em uma cientificidade licenciada pela mathésis universalis, ou seja, pela validade objetiva da construção matemática, ganha corpo na exata medida daquilo que Francis Bacon, em 1620, já ditara no Novum Organum: "a natureza não se vence, senão quando se lhe obedece". É no campo da experimentação - metodologia do homem moderno e ilustrado - que 
se buscará descobrir as leis próprias da natureza.

As grandes descobertas realizadas na época pós-renascentista, junto aos primeiros passos dados em direção a um novo modelo de sociabilidade liberal, devem ser atribuídas ao espaço recém conquistado para a efetuação da dinâmica inerente ao espírito racional-construtivo, reprimido ao longo da Idade Média. (Flickinger, 1998, p. 368-3691

A experiência, enquanto um dado oferecido ao espírito racional-construtivo, é possibilidade de apreensão do objeto exclusiva do sujeito e a fundamentação do conhecimento é resultado da atividade racional. Enfim, podemos afirmar, sem descomedimento ou exagero, que até o século XIX a fé no potencial construtivo da razão, embora tenha adversários, não encontra barreiras; pelo contrário, o sujeito racional, dono do potencial abarcador do objeto por meio de sua racionalidade, figura como princípio último, dominando os campos diversos dos saberes necessários à nova sociabilidade que se instala.

Para Kesselring (2000), “a divisão do mundo em duas partes, o mundo dos corpos materiais e o mundo do pensamento, é sintoma da cisão entre homem e natureza" (p. 161). A natureza restringe-se à parte "mundo dos corpos materiais"; o pensamento, por outro lado, não pertence à natureza. A convicção aristotélica de que os princípios que regem a natureza são abertos ao logos humano não faz mais sentido na visão moderna de mundo robustecida pelo cartesianismo. Assim, somente o homem é dotado de razão e capaz de conhecer. Cabe a ele assumir a responsabilidade pela interpretação e construção da realidade e também pelo desenvolvimento histórico. É tarefa humana não só o situar-se do homem no mundo, mas situar o mundo em função de sua própria capacidade de conhecer. Touraine (1994) pensa a modernidade como o "reino da razão". Fruto de um processo construtivo de conhecimento, resultado da transformação da visão cosmogônica de mundo em visão cosmológica, a modernidade é o fenômeno pelo qual o homem, enquanto sujeito, assume o papel determinante na relação de conhecimento. 0 objeto não mais determina e precede o sujeito, como algo estanque e independente dele; o sujeito é, agora, o determinante do próprio objeto, submetendo-o às suas condições e possibilidades, sempre com o intuito de fazer ciência - "ciência é um conhecimento que inclui, em qualquer forma ou medida, uma garantia da própria validade. A limitação expressa pelas palavras 'em qualquer forma ou medida' inclui-se aqui para tornar a definição aplicável à ciência moderna que não tem pretensões de absoluto." (Abbagnano, 1982, p. 126)

A revolução copernicana protagonizada pela filosofia kantiana para explicar a forma como o conhecimento acontece propicia um deslocamento para a figura do sujeito cognoscente, o depositário das formas do conhecimento. Dessa forma, o mundo não possui sentido algum, a não ser aquele que damos a ele, o que, 
levado às últimas consequências, traz-nos “a dúvida quanto a se o meio ambiente poderia tornar-se um tema sério de investigação científica[...] Encontra-se aí também o motivo da tentação frequente de romantizar a natureza de modo irracional". (Flickinger, 1998, p.380)

\section{Contradições e deslocamentos necessários}

A recuperação até aqui realizada, em largos traços, da trajetória do relacionamento sujeito-objeto, a partir dos sentidos predominantes que 0 conceito de natureza adquiriu ao longo da história da filosofia oferece-nos indícios, à primeira vista paradoxais, de que há progresso e continuidade das teorias, ao mesmo tempo em que ocorrem rupturas e superação de um pensamento filosófico por outro. Trata-se de um movimento semelhante ao apontado por Thomas Kuhn:

Ao aprender um paradigma, o cientista adquire ao mesmo tempo uma teoria, métodos e padrões científicos, que usualmente compõem uma mistura [inextricável]. ${ }^{1}$ Por isso, quando os paradigmas mudam, ocorrem alterações significativas nos critérios que determinam a legitimidade tanto dos problemas como das soluções propostas. (Kuhn, 2006, p. 144)

Acompanhados daqueles autores que, como Paul Ricoeur, em Historia y Narratividad, entre outras de suas obras, atribuem um papel epistemológico importante à história, consideramos que assumir uma posição metodológica hermenêutica, ou uma doutrina de interpretação, não significa abandonar um pensamento em prol de outro, mas buscar sentido pela interpretação dos fatos e não apenas contentar-se com sua simples explicação. Pela leitura hermenêutica da relação homem-natureza nos diferentes períodos históricos, podemos alcançar a obstinação de interpretar, compreender e separar as ciências humanas da suposta hegemonia das ciências naturais. Tal escolha baseia-se em uma condição específica do trabalho das ciências humanas, qual seja, o comprometimento do próprio pesquisador no objeto de sua investigação.

Tornar possível um pensamento sobre a educação ambiental que escape aos modelos preconcebidos e impostos pelas ciências naturais implica o recurso à linguagem. 0 pensamento sobre a natureza, frequentemente, tem permanecido restrito a um sistematismo anacrônico, sendo necessário, portanto, romper com

1. Optamos, aqui, por corrigir um pequeno deslize da edição brasileira, que traduz "inextricable mixture" por "mistura inexplicável", alterando consideravelmente a ideia do autor. No texto original, lê-se: "In learning a paradigm the scientist acquires theory, methods, and standards together, usually in an inextricable mixture. Therefore, when paradigms change, there are usually significant shifts in the criteria determining the legitimacy both of problems and of proposed solutions." (Kuhn, 1970, p. 109) 
tal lógica a fim de possibilitar uma reflexão mais produtiva. Faz-se necessário invocar critérios de interpretação de uma normatividade implícita quanto aos fins da socialização e convivência, inclusive, entre homem e meio ambiente. Tal escolha não representa retrocesso, retorno ou o abandono de certas concepções em favor de outras, mas a incorporação de um fio condutor que possibilita, independentemente da concepção de natureza assumida e do método de educação ambiental desenvolvido, aproximar o homem da natureza através da subjetividade e despertar a amorosidade que permite humanizar a natureza e, principalmente, naturalizar o homem. Por essa razão, a hermenêutica leva em conta, por exemplo, a história e a linguagem como itens organizadores do acesso humano ao mundo social, como planos não objetificáveis por princípio. "Nesse sentido, a hermenêutica parte do pressuposto que toma como ponto de partida a impossibilidade de o sujeito conhecedor colocar-se fora desse seu contexto, querendo distanciar-se dele a fim de o dominar." (Flickinger, 1998, p. 382)

No pensamento moderno, a razão torna-se o ponto de referência para a validade de qualquer ação humana, legitima e justifica as relações de poder, de dominação e de opressão. A sensibilidade, por seu turno, é a dimensão combatida, reprimida sistemática e recidivamente na tradição ocidental. No entanto, é a própria expressão humana da natureza. A tradição filosófica do ocidente testemunha uma luta incessante da razão contra os sentidos e a corporeidade e, portanto, contra a natureza (Schütz, 2009). Isso pode ser verificado, tanto no plano da epistemologia quanto no âmbito da filosofia social.

A tradição filosófica ocidental poderia, muito bem, ser lida como o percurso do esquecimento, do recalque dos sentimentos, da dimensão sensível do homem e, portanto, da natureza, uma vez que a própria natureza é combatida através da disputa pelo não predomínio da sensibilidade. Por isso, urge recuperá-la.

Reabilitar a dimensão da sensibilidade humana pode, além de oferecer um novo aporte às lutas emancipatórias, fornecer as bases para uma nova concepção de razão, e mesmo de filosofia, como foi a proposta de Feuerbach. Se, na tradição hegemônica no ocidente, a razão só pode ser afirmada à medida que expulsava de si a integralidade do humano, à medida que se fazia unilateral e negava o ser humano em sua naturalidade e à medida que degradava a natureza externa ao homem a um mero objeto, então é a própria razão com a concepção de sujeito por ela pressuposta, que precisa ser repensada. (Schütz, 2009, p. 174)

O predomínio exacerbado da racionalidade objetiva resultou em processo desumanizante, que compartimenta e mutila o ser humano. Construir uma cultura que não menospreza ou diminui o potencial de sensibilidade humana implica pensar uma razão que pode conviver com tudo o que é humano - sua sensibilidade, sua amorosidade e a percepção da alteridade, na qual se encontra a natureza. Paralelamente ao mainstream filosófico moderno, uma gama de 
autores tem explorado a possibilidade de afirmar a realidade sensível, buscando uma via emancipatória, por meio do cultivo de todas as dimensões do humano, em lugar da exclusividade da razão. 0 modo de percepção do homem em relação à natureza torna-o mais humano, mais sensível, mais integral, permite aproximar-se da totalidade do seu ser. Sem dúvida, trata-se de uma orientação mais modesta do que aquela do modelo iluminista ${ }^{2}$ de ciência, porém mais eficaz, no sentido da recuperação de uma posição que toma o outro, o estranho de si, a sério. Imprescindível recordar as posições de Rousseau (1712-1778) e Schopenhauer (1788-1860) em relação à natureza, a uma filosofia da natureza - o primeiro platônico e o segundo, possivelmente um romântico pessimista e creditário da filosofia materialista francesa, como a de Holbach. 0 fato é que a ambos, muitas vezes, é imputada a rotulação de "românticos". Outro fato comum aos dois autores é que nenhum deles desejaria ver suas teses defendidas nos círculos filosóficos: "Não se deve esquecer como Schopenhauer ficava horrorizado só de imaginar que sua obra se tornasse o pasto dos professores de filosofia" (Lefranc, 2002, p. 20). Rousseau, por sua vez, manteve-se sempre prudente em relação a envolvimentos teóricos maiores com os filósofos do seu tempo. Porém, o pensamento dos dois autores representa o que há de especial na linhagem do racionalismo crítico ou de uma filosofia que questiona o mecanicismo a partir do qual compreendemos o conceito de natureza e propõe novas abordagens ante 0 senhorio e poder humano sobre ela.

Rousseau modela sua antropologia conectada à mãe-natureza, fonte de inspiração para todas as ações humanas e, nesse sentido, subordina toda a explicação a respeito da movimentação do homem às exigências do natural. A submissão do homem aos princípios e ditames naturais é que, otimisticamente, poderia impedir a corrupção dos costumes e a depravação da alma. Por isso, pudesse o homem permanecer incessantemente no "estado de natureza", mais próximo encontrar-se-ia daquilo que a natureza dele exige. A liberdade civil, entretanto, o interpela e, por isso, não deixa de ser “[...] um grande e belo espetáculo ver o homem sair, de qualquer maneira, do nada, por seus próprios esforços; dissipar, com as luzes da razão, as trevas nas quais a natureza o envolvera [...]" (Rousseau, 1983, p. 249). É inegável que Rousseau, embora almeje preservar o lugar de onde saímos (a natureza), encontra-se embalado pelos ares iluministas, embora cauteloso em relação aos excessos que o progresso das ciências e das artes pudesse acarretar.

2. Razão, progresso e liberdade são alguns dos conceitos que definem o lluminismo do século XVIII, enquanto um movimento social-cultural, filosófico-crítico e politicamente progressista. Cabe assinalar, entretanto, que essas ideias não foram prerrogativas e exigências do século do Iluminismo (primeiramente, no século XVIII, um movimento francês). Não é de espantar que, se levados em conta os três ideais acima assinalados, podemos mencionar um iluminismo grego, por exemplo, uma vez que a Grécia Antiga empunhava bandeiras com essas mesmas exigências antropológicas e políticas. Na realidade, o lluminismo define-se como um movimento que perpassa e ultrapassa toda a história da razão. 
Arthur Schopenhauer, filósofo para quem a natureza é gênese oculta da ação humana (Über den Willen in der Natur), realiza analogias e paralelismos entre fenômenos naturais e humanos a fim de comprovar a aleatoriedade dos mesmos e oferece um sentido dúbio à liberdade humana. No impulso de uma filosofia animista, conforme a ele se refere Bachelard (1996, p. 190), Schopenhauer declara a natureza múltipla, como ente que opera por sua própria vontade, “joga dados" e impõe um script natural ao homem. No instante em que nossa inteligência surpreende-se com a correspondência de tamanho, forma ou arranjo entre objetos, ou seja, com a simetria introduzida pela natureza em um organismo ou no momento em que a inteligência se surpreende com o fim que o organismo realiza, ela se espanta, em última análise, com a variedade de fenômenos sob os quais o próprio intelecto apreende a unidade da vontade. Dizendo de outro modo, a inteligência humana admira-se e espanta-se com sua própria obra, mesmo quando atribui a ordem da natureza a uma inteligência divina.

$\mathrm{Na}$ esteira de Schopenhauer, outros autores alemães pertencentes ao movimento literário Drang und Sturm anunciam o primado da expressão individual e subjetividade sobre a ordem natural do racionalismo. Tal posição filosófica, aparentemente espontânea, enseja até mesmo novas orientações quanto à formação humana, uma vez que o romance de formação (Bildungsroman) é representativo de uma relação diferenciada (romântica) entre homem e natureza.

Tensões e contradições, como as que vimos mencionando, no decorrer do texto e que surgiram historicamente, oferecem bases e subsídios para o entendimento dialético da relação do homem contemporâneo com a natureza, bem como uma fundamentação mais sólida para a educação ambiental. Se consideramos, por exemplo, a filosofia social marxiana, podemos assegurar que uma de suas importantes linhas de preocupação é a humanização dos sentidos do homem, a fim de despertar a sensibilidade humana compatível com toda a riqueza do ser natural e humano. Nessa perspectiva, Marx apresenta, em consonância com Feuerbach, um deslocamento do horizonte emancipatório moderno: passa-se do domínio da natureza e do desprezo dos sentidos para o despertar da sensibilidade nos processos emancipatórios.

Marcuse (1999) compartilha da mesma reflexão, quando assinala que, com a transformação da estrutura instintiva, transformar-se-ia também a atitude básica, filosoficamente primitiva ou antiga, da filosofia platônica, de conhecimento do meio ambiente, como fruto da interação do homem e natureza.

A partir do exposto, percebe-se que a superação da exclusividade da razão requer uma relação qualitativamente diferente do ser humano consigo mesmo enquanto corporeidade, através da qual toda a natureza externa faz-se presente e valoriza o ser sobre o pensar, deixando-se afetar pela realidade. Quando chegamos à nossa autoconsciência individual, experimentando-nos enquanto existentes no mundo existente, os níveis do sentir, do intuir e da reflexão, elementos da 
razão que podem despertar para uma sensibilização frente à natureza, tal como Schelling os desenvolve de modo transcendental-filosófico enquanto conteúdos da consciência, encontram-se já integrados em nossa experiência da natureza. 0 próprio Schelling reconstrói os níveis das dimensões da experiência da natureza, quais sejam: sensação, intuição, reflexão, experiência da práxis, vontade, direito e história, na produtividade estética da arte. Nesse sentido, o ser humano não pode mais ser reduzido a categorias lógicas e precisa expressar sentimentos, mostrar subjetividades, necessita realizar correspondências entre corporeidade e amorosidade para consigo, para com o outro e para com a natureza. 0 homem apresenta cinco sentidos e a humanidade da natureza se manifesta através de todos eles. Com o despertar da sensibilidade, promover-se-á o questionamento das abordagens compartimentalistas, reducionistas e individualistas na compreensão da relação homem-natureza. Uma unidade dinâmica através da manifestação na natureza interna do ser humano mediante a manifestação da sensibilidade e da introspecção é o que a educação ambiental e sua fonte inicial inspiradora, a pedagogia, devem buscar.

A prática educativa atual funciona de acordo com a lógica científica instrumental que fragmenta a realidade, ancora-se no capitalismo, mercantiliza todos os seres vivos. Logo, é importante a associação das iniciativas que trabalham com esferas afetivas e comportamentais, num movimento de mudança individual e coletiva pela práxis revolucionária, que harmoniza homem e natureza. Nessa perspectiva, pensamos que o processo de conscientização do indivíduo na direção de uma consciência ecológica crítica passa, necessariamente, pela mudança na sua visão de mundo. A consciência ecológica não é unicamente a tomada de consciência da degradação da ambiente natural, mas também do caráter da nossa relação com ele (Morin, 1980). E essa relação passa por elementos que despertam a sensibilidade e a amorosidade entre homem e natureza.

É necessário abandonar a visão cartesiana que se manifesta na visão utilitarista e mecanicista que possuímos a respeito da natureza e incorporar elementos sensíveis que permitam o despertar de uma nova relação/compreensão com a natureza, sempre viva no ser humano. (Nunes, 1988, p. 22)

Sensibilizar a educação ambiental, ou melhor, resgatar a natureza interior do ser humano poderá ser o grande elo de fortalecimento entre a pedagogia e a educação ambiental. 0 uso da sensibilidade no enfrentamento da problemática reestabelece o vínculo e a percepção de uma totalidade homem-natureza ora esquecida, leva a práticas e ações coerentes, harmônicas e conscientes em relação à natureza e permite a visibilidade do componente ambiental nas ações pedagógicas. 


\section{Referências}

ABBAGNANO, Nicola. Dicionário de Filosofia. São Paulo: Ed. Mestre Jou, 1962.

ABRANTES, Paulo. Imagens de natureza, imagens de ciência. Campinas: Papirus, 1998. BACHELARD, Gaston. A formação do espírito científico. Rio de Janeiro: Contraponto, 1996.

COLLINGWOOD, Robin George. Ciência e Filosofia. Lisboa: Editorial Presença, s/d. A idéia de natureza. Lisboa: Editorial Presença, s/d.

FLICKINGER, Hans-Georg. Sociedade, educação e meio ambiente. In: MARCON, Telmo. (Org.). Educação e universidade - práxis e emancipação. Passo Fundo: Editora da UPF, 1998. p. 365-384.

JAEGER, Werner. La teología de los primeros filósofos griegos. México: Fondo de Cultura Económica, 1952.

KANT, Immanuel. Crítica da Razão Pura. 5. ed. Lisboa: Fundação Calouste Gulbenkian, 2001.

KESSELRING, Thomas. 0 conceito de natureza na história do pensamento ocidental. Episteme, Porto Alegre, n.11, p. 153-173, jul./dez. 2000.

KUHN, Thomas. A estrutura das revoluções científicas. 9. ed. São Paulo: Perspectiva, 2006.

The Structure of Scientific Revolutions. Second Edition, Enlarged. Chicago: The University of Chicago Press, 1970.

LARA, Tiago Adão. Caminhos da razão no Ocidente: a filosofia nas suas origens gregas. Petrópolis, RJ: Vozes, 1989. 4. ed. Coleção Caminhos da Razão. V. 1.

LAYRARGUES, Philippe Pomier. A natureza da ideologia e a ideologia da natureza: elementos para uma sociologia da educação ambiental. Campinas: Unicamp, 2003. (Tese de Doutorado em Ciências Sociais).

LEFRANC, Jean. Compreender Schopenhauer. Petrópolis, RJ: Vozes, 2002.

LENOBLE, Robert. História da idéia de natureza. Lisboa: Edições 70, 2002.

LOUREIRO, Carlos Frederico Bernardo. Educação ambiental transformadora. In: LAYRARGUES, Philippe Pomier. (Org.). Identidades da educação ambiental brasileira. Brasília: Ministério do Meio Ambiente, 2004. p. 65-84.

MARCUSE, Herbert. Eros e civilização: uma interpretação filosófica do pensamento de Freud. 8 ed. Rio de Janeiro: LTC Editora, 1999.

MARX, Karl; ENGELS, Friedrich. A ideologia alemã: crítica da mais recente filosofia alemã em seus representantes Feuerbach, Bruno Bauer e Stirner, e do socialismo alemão em seus diferentes profetas. São Paulo: Boitempo, 2007.

MINISTÉRIO DA SAÚDE. Conselho Nacional de Saúde. Subsídios para construção da política nacional de saúde ambiental. Série B. Textos Básicos de Saúde. Brasília, 2007.

MORIN, Edgar. O método II - a vida da vida. 2. ed. Portugal: Publicações Europa-América, 1980.

NUNES, Ellen Regina Mayhé. Educação Ambiental: princípios e objetivos. Revista de Educação AEC, Brasília, DF, ano 17, n. 68, p. 19-28, abr./jun. 1988. 
PEDRINI, Alexandre de Gusmão. Trajetórias em Educação Ambiental. In: PEDRINI, Alexandre de Gusmão (Org.) Educação Ambiental: reflexões e práticas contemporâneas. 5.ed. Petrópolis: Vozes, 2002.

PICHT, Georg. Der Begriff der Natur und seine Geschichte. Stuttgart: Klett-Cotta, 1989. RICOEUR, Paul. Historia y Narratividad. Barcelona: Paidós, 1999.

Rousseau, Jean-Jacques. Do Contrato Social (1757); Ensaio sobre a origem das línguas (1759); Discurso sobre a origem e os fundamentos da desigualdade entre os homens (1755); Discurso sobre as ciências e as artes (1749). Trad. Lourdes Santos Machado; introduções e notas de Paul Arbousse-Bastide e Lourival Gomes Machado. 3. ed. São Paulo: Abril Cultural, 1983. (Coleção Os Pensadores)

SAVIANI, Dermeval. Educação: do Senso Comum à Consciência Filosófica. 13. ed. Campinas: Autores Associados, 2000.

SCHELLING, Friedrich Wilhelm Joseph von. Filosofia da arte. São Paulo: Edusp, 2001. Sistema del idealismo transcendental. Barcelona: Anthropos, 1988.

SCHÜTZ, Rosalvo. Sensibilidade emancipatória: Schelling, Feuerbach e Marx à contrapelo da tradição. In: CHAGAS, Eduardo; REDYSON, Deyve; DE PAULA, Márcio (Orgs.). Homem e natureza em Ludwig Feuerbach. Fortaleza: Edições UFC, 2009. p. 171212.

SILVA, Arlindo et all. Reestruturação da cooperação técnica em saúde ambiental entre FUNASA, estados e municípios. Brasília: 2003. Disponível em <http://www.semasa. sp.gov.br/Documentos/ASSEMAE/Trab_01.pdf>. Acesso em 22/12/2009.

TOURAINE, Alain. Crítica da Modernidade. Petrópolis, RJ: Vozes, 1994.

Recebido em abril de 2013

Aprovado em julho de 2013

Denise Gamio Dias é doutora em Educação pela Universidade Federal de Pelotas. Atualmente faz estágio pós-doutoral no Programa de Pós-Graduação em Parasitologia da Universidade Federal de Pelotas e membro do Grupo de Pesquisa Filosofia, Educação e Práxis Social (FEPRáxiS). Email: denisegamiodiasQhotmail.com

Neiva Afonso Oliveira é professora do Programa de Pós-Graduação em Educação da Universidade Federal de Pelotas e líder do Grupo de Pesquisa Filosofia, Educação e Práxis Social (FEPRáxiS). Email: neiva.afonso.oliveiraldgmail.com

Avelino da Rosa Oliveira é doutor em Educação, professor titular da Universidade Federal de Pelotas e membro do Grupo de Pesquisa Filosofia, Educação e Práxis Social (FEPRáxiS). Email: avelino.oliveirađagmail.com 